\title{
Alba-la-Romaine - La Grande Terre, RD 725
}

Fouille préventive (2013)

\section{Antoine Ratsimba}

\section{(2) OpenEdition}

\section{Journals}

Édition électronique

URL : https://journals.openedition.org/adlfi/14541

ISSN : 2114-0502

Éditeur

Ministère de la Culture

Référence électronique

Antoine Ratsimba, « Alba-la-Romaine - La Grande Terre, RD 725 » [notice archéologique], ADLFI.

Archéologie de la France - Informations [En ligne], Auvergne-Rhône-Alpes, mis en ligne le 24 avril 2015, consulté le 29 juillet 2021. URL : http://journals.openedition.org/adlfi/14541

Ce document a été généré automatiquement le 29 juillet 2021.

(c) ministère de la Culture et de la Communication, CNRS 


\section{Alba-la-Romaine - La Grande Terre, RD 725}

Fouille préventive (2013)

Antoine Ratsimba

NOTE DE L'ÉDITEUR

Organisme porteur de l'opération : Inrap

1 À la fin de l'année 2011, un diagnostic archéologique a été réalisé par Éric Durand (Inrap) à $400 \mathrm{~m}$ au sud-ouest de l'actuel village d'Alba-la-Romaine. Il s'est déroulé en amont d'un projet d'urbanisation initié par la commune, qui consistait en la mise en place de voiries et réseaux (PVR) en vue de l'implantation de plusieurs maisons individuelles. Il a concerné 48 parcelles cadastrales réparties sur une surface de près de 7 ha. La fouille qui précédait l'aménagement d'une de ces habitations s'est déroulée sur une surface de $800 \mathrm{~m}^{2}$.

2 Cette opération, réalisée entre les mois de juin et juillet 2013, a mis au jour des vestiges de trois occupations chronologiquement distinctes.

3 La principale découverte est une voie de l'âge du Fer orientée nord-nord-est - sud-sudouest. Observé sur une longueur de $30 \mathrm{~m}$, cet axe de circulation se présente sous la forme d'un vaste creusement d'environ $1 \mathrm{~m}$ de profondeur, aux parois évasées et au fond plat. À l'ouverture, sa largeur avoisine $6 \mathrm{~m}$. À la base, sur $3 \mathrm{~m}$ de largeur, les niveaux de bandes de roulement, constitués de gravillons et graviers, sont marqués de plusieurs ornières. La fouille méthodique de cet ouvrage a abouti à la discrimination de différents états de fonctionnement. Parmi le matériel récolté, la présence de céramique importée (amphores massaliètes et étrusques) et de vaisselle tournée (grise monochrome et pâte claire) a permis de proposer une datation centrée sur la première moitié du v s. av. J.-C.

4 Une fosse polylobée d'environ $15 \mathrm{~m}^{2}$ a été mise au jour au nord-ouest du chemin creux. Cette structure ayant livré très peu de matériel, sa datation reste incertaine. Antérieure 
à l'axe de voirie, la présence de céramique non-tournée à fond plat la rattache à la Protohistoire. Les datations ${ }^{14} \mathrm{C}$ actuellement en cours permettront de préciser sa chronologie.

5 Enfin, deux linéaments fossoyés du Haut-Empire sont à mettre en relation avec le parcellaire de la villa du Clos repéré au diagnostic.

6 Si l'exiguïté de la parcelle décapée a limité la portée de nos observations, les opérations à venir permettront de mettre en valeur ces premières données.

\section{INDEX}

lieux https://ark.frantiq.fr/ark:/26678/pcrtSEeAipsBlD, https://ark.frantiq.fr/ark:/26678/ crtB8WDyqd6u9, https://ark.frantiq.fr/ark:/26678/pcrtjlOy60eKRi, https://ark.frantiq.fr/ark:/ 26678/pcrtFwuExfWRlE

nature https://ark.frantiq.fr/ark:/26678/pcrtcJxzOpgs7T

Année de l'opération : 2013

chronologie https://ark.frantiq.fr/ark:/26678/pcrtHlenwSnkDM, https://ark.frantiq.fr/ark:/ 26678/pcrtW9SpIgIk7Q, https://ark.frantiq.fr/ark:/26678/pcrtxVmyWBbIQq, https:// ark.frantiq.fr/ark:/26678/pcrtxT02uJOogm, https://ark.frantiq.fr/ark:/26678/pcrtof7EHNsS2e, https://ark.frantiq.fr/ark:/26678/pcrtZTmusVUU24 sujets https://ark.frantiq.fr/ark:/26678/pcrtjclbYvph1S, https://ark.frantiq.fr/ark:/26678/ pcrt1eKrSANesO, https://ark.frantiq.fr/ark:/26678/pcrt1DMOWvDF4j, https://ark.frantiq.fr/ ark:/26678/pcrtms2OAv82PY

\section{AUTEURS}

\section{ANTOINE RATSIMBA}

Inrap 